\title{
WT limb-blood syndrome
}

INSERM

\section{Source}

INSERM. (1999). Orphanet: an online rare disease and orphan drug data base. WT limbblood syndrome. ORPHA:3466

A rare constitutional aplastic anemia disorder characterized by severe hypo/aplastic anemia or pancytopenia associated with skeletal anomalies (such as radial/ulnar defects and hand/digit abnormalities) and an increased risk of leukemia. There have been no further descriptions in the literature since 1995. 